\title{
Assessment Risk Factors of Abdominal Compartment Syndrome During Resuscitation Phase of Burned Patients
}

\author{
Zeinab R. Ahmed ${ }^{1}$, Youssef S. Hassan ${ }^{2}$, Mogedda M. Mehany ${ }^{3}$ \& GHada S. KHalaf ${ }^{4}$. \\ ${ }_{1}$ B.Sc., Nursing Specialist, at Abnoub Secondary Nursing School, Assiut Governorate, Egypt. \\ ${ }^{2}$ Professor of plastic surgery of Assiut University hospital Egypt. \\ 3 Assistant professor of critical care nursing, Faculty of Nursing, Assiut University Egypt. \\ ${ }^{4}$ Lecturer of critical care Nursing, Faculty of Nursing, Assiut University Egypt.
}

\begin{abstract}
Background: Raised Intra-abdominal pressure in patients with severe burns can lead to organ dysfunction and can affect all organ systems due to massive IV fluid resuscitation. The aim of study was assess the risk factors of abdominal compartment syndrome during resuscitation phase of burned patients. Research design: exploratory research design was used to achieve the objectives of the study. Subjects: All available adult burned patients admitted to Burn unit who with (45) patients. Tools: two tool designs us to identify risk factors of abdominal compartment syndrome during resuscitation phase of burned patients, data collected through 6 months. Results: the result show that Vast Majority of patients had flame as a reason of burns with percentage $96.6 \%$. Less than half of patients were at lower and upper limbs burned of body region with percentage $40.0 \%$. In addition, result show that the prevalence of Intra-abdominal hypertension in severe burn patients is with percentage $68.8 \%$ respectively. The findings of the study revealed that when increase BMI, TBSA and IV fluid increase IAP. Conclusion: Patients with $>20 \%$ TBSA burned presented a very high prevalence of IAH. Recommendations: The Burns Unit needs to design protocols for screening, monitoring and management of Intra-abdominal hypertension.
\end{abstract}

Key words: Abdominal Compartment Syndrome, Fluids Resuscitation, Intra-Abdominal Hypertension \& Severe Burns.

\section{Introduction}

Severely burned patients usually develop Intraabdominal hypertension and abdominal compartment syndrome (IAH/ACS) within 48 hours after injury. The use of excessive fluid resuscitation with severe burns injury leads to increase in capillary permeability that contributes to extensive edema formation and intra-peritoneal accumulation of "third-space" fluid. This patient particularly vulnerable to the development of IAH and ACS and cardiovascular, respiratory, and renal system dysfunction (Malbrain et al., 2015 \& mcbeth et al., 2014).

The factors leads to IAH and ACS in burned patient are large volumes of intra venous fluid resuscitation or total body surface area burned is larger than $60 \%$. The second main factor is compliance decreasing burns of the abdominal or thoracic wall. Severe third degree trunk burns result in limited thoracoabdominal eschars which greatly reduce the abdominal wall compliance resulting in intraabdominal hypertension (Mbiine et al., 2017 \& James et al., 2012).

The incidence of IAH and ACS among patients with burns is unknown, because it depends on the severity of burn injury, the method and frequency of Intraabdominal pressure measurement, the exact definition used to define IAH, and the duration of IAP monitoring (Malbrain et al., 2015).
Abdominal compartment syndrome (ACS) and intraabdominal hypertension (IAH) are effect on organ systems in burned patient, which causes progressive hypoperfusion and ischemia of the intestines and other peritoneal and retroperitoneal structures. The effects of IAH are not limited just to the intraabdominal organs. Increase IAP affects renal blood flow, urinary output is an unreliable index of the preload and intravascular volume resulting in the loss of an important physiologic parameter (Malbrain et al., $2015 \&$ kollias et al., 2015).

Intra-abdominal pressures monitoring is important in critically ill burned patients because Intra-abdominal hypertension has been recognized as a contributor to burns morbidity and mortality. As a result, there is growing interest in the field of intra-abdominal hypertension in severe burns and its impact on patient care and outcome (Mbiine et al., 2017).

There is a lack of knowledge among health professionals in regard to Intra-abdominal pressure measurement methodology and lack knowledge about Intra-abdominal hypertension and its clinical implications. There is still no consensus on a standardized methodology to measure Intraabdominal pressure, but there are strong recommendations on the importance of this measurement and its clinical significance for hospitalized patients. (Talizin et al., 2018). 
Nurses caring for any of these patients must focus on prevent ACS by closely monitoring for intraabdominal pressure, organs function and recording daily intake and output and assessing cumulative fluid balance are important nursing actions in managing these patients (Koehl, 2012).

\section{Significance of the study}

Intra-abdominal hypertension and abdominal compartment syndrome are frequently seen devastating complications in the severely injured burn patients. The prevalence of abdominal compartment syndrome among patients with more than $20 \%$ TBSA burned ranged from $4.1 \%$ to $16.6 \%$ according to World society abdominal compartment syndrome. So the study will be conducted to recognition risk factors of abdominal compartment syndrome and it will provide us with information about the important of monitoring Intra-abdominal pressure to preventing this dangerous complication and should receive high priority of care to severe burn patients.

\section{Aim of study}

The aim of this study is to assess the risk factors of abdominal compartment syndrome during resuscitation phase of burned patients.

\section{Research question}

What are the risk factors of abdominal compartment syndrome during resuscitation phase of burned patients?

\section{Subject \& Methods}

\section{Technical design}

This design involves the research design, subject and data collection tools.

\section{Research Design}

Exploratory research design was used in this study.

\section{Setting}

The present study was carried out in Burn unit at Assiut university hospital. Located on the ground floor of the hospital and consisted of four patient room and 16 beds

\section{Subjects}

Purposive sample included $(n=45)$ Burned patients were admitted in burn unit during 6 months. The study included patients with age $>20$ years old, more than $20 \%$ of total body surface area burned and Have indwelling urine catheter in place.

\section{Exclusion criteria which includes patients}

1. Recent bladder surgery.

2. Minor and unlikely to survive $24 \mathrm{hrs}$.

3. Pregnant.

4. Unable to lay flat for critical reason.

\section{Data collection tools}

It consist of two tools used in this study were developed by the researcher based on reviewing of the relevant literatures.

Tool one: A structure questioner sheet

It is a self-administer sheet adapted by(Espinoza et al., 2017\& Barbosa et al.,2009) and modified by the researcher.it used to assess the patient conditions to form base line data to be compared with this tool was include five part

Part I: it consisted of Personal characteristics data included Patient's code number, sex, age, Height, weight, BMI, level of education, and occupation. Clinical data including past history, date of admission, previous abdominal pelvic surgical condition, and date of discharge, length of stay, mortality rate and complications.

Part II: Assessment vital signs included pulse rate, blood pressure, respiratory rate, and temperature.

Part III: Assessment laboratory investigations included complete blood picture, blood sugar and kidney functions which include (urea, creatinine).

Part IV: Assessment of amount of IV fluid intake during first 24 hours of injury. Amount urine output during first 24 hours of injury.

Part V: assessment burn characteristic included nature of incident, Place of incident, Origin of burns, Degree of burn, Burned body region, Total body surface area (\%TBSA).

Tool two: Assessment intra-abdominal pressure This tool used in this study was developed by the researcher based on reviewing of the relevant literatures. It consist of two part

Part one: This part was used to assess intraabdominal pressure and grades of intra-abdominal hypertension(IAH), Grade 0 IAP (less than 12) ,Grade 1 IAP (12-15 mmHg), Grade 2 IAP (16-20 $\mathrm{mmHg})$, Grade 3 IAP $(21-25 \mathrm{mmHg})$ and grade 4 IAP ( more than $25 \mathrm{mmHg}$ ) (Berry \& Fletcher, 2012).

Part two: This part was used to assess risk factors of Intra-abdominal hypertension and abdominal compartment syndrome through monitoring intraabdominal pressure.

Preparatory phase

Permission was obtained to collect data before starting this study, it was necessary to secure the approval of authorities in the setting of the study. A review of the current and past available literature on the various aspects of the problem using textbook, articles and magazines were done in order to give a clear picture about the research problem and to develop the study tools. Tool was constructed by the researcher and revised by jury of experts in the field of the study. 
- Validity of tool was estimated by 5 experts in Critical and emergency situations department

- Reliability was tested for tools by using Cronbach's alpha (tau-equivalent reliability) coefficient ( $\mathrm{r}=$ $0.853,0.713$ and 0.725 respectively) which its internal consistency "acceptable".

\section{Pilot study}

A pilot study was carried out before starting of data collection phase including $10 \%$ of sample in selected setting to evaluate the applicability and clearly of tools. According to the result of pilot study, the necessaries modifications were done.

\section{Ethics administrative}

Research proposal was approved from ethical committee in the faculty of nursing, Assuit University. Oral consent was obtained from patients or guidance that participated in the study, after explaining the nature and the purpose of the study. Confidentiality and anonymity was assured. Patients had the right to refuse to participate and or withdraw from the study without any rational any time. There was no risk for study subject during application of the study.

\section{Field work}

Data were collected in six months from July 2017 to December 2017.The data were collected from the first 24 hours of injury. The researcher assessed each patient from the first 24 hours of admission and record patient personal characteristics and clinical data before any data collection by taking this information from her sheet. Assessed IV fluids intake during the first 24 hours of admission that divided into three times according to parkland formula and urine output.The researcher assessed vital signs were measured three times during first 24 hours of admission and laboratory investigations. The researcher assessed characteristics of the burn included causes of burns, Degree of burn, and burned body regions. The researcher assessed IAP through measure it by using urinary catheter. Measure IAP was done three time during the first 24 hours of admission (at admission patient, after 8 hours and after 24 hours) The measurements were taken with the patient lying supine on a completely flat bed, the iliac crest junction with the mid axillary line was used as the zero reference point, and the readings taken at the end of expiration (Mbiine et al., 2017) The researcher assessed risk factors of abdominal compartment syndrome during resuscitation phase of burned patients through monitoring intra-abdominal pressure when be greater than $20 \mathrm{mmhg}$ is consider ACS and assessed complication, length of stay and mortality rate during the patient stay in hospital.

\section{Statistical design}

The data obtained had reviewed, prepared for computer entry, coded, analyzed and tabulated. Descriptive statistics (frequencies and percentages, mean \& standard deviation, Pearson correlation coefficients, Independent sample T-test, Chi-square and One-way-ANOVA tests i.e.) were done using computer program (SPSS) version (25). It's considered significant when $P$. value less than (0.05).

\section{Results}

Table (1): Percent distribution of personal characteristic of studied patients.

\begin{tabular}{|c|c|c|}
\hline \multirow{2}{*}{ Items } & \multicolumn{2}{|c|}{ Studied patients $(n=45)$} \\
\hline & No. & $\%$ \\
\hline \multicolumn{3}{|l|}{ Age: } \\
\hline Mean \pm SD & \multicolumn{2}{|c|}{$39.1 \pm 15.2$} \\
\hline \multicolumn{3}{|l|}{ Gender: } \\
\hline Female & 20 & 44.4 \\
\hline Male & 25 & 55.6 \\
\hline \multicolumn{3}{|l|}{ Classification BMI (kg/m2): } \\
\hline Normal range & 7 & 15.6 \\
\hline Overweight $\quad(25.00-29.99)$ & 13 & 28.9 \\
\hline$(30.00)$ & 8 & 17.8 \\
\hline Obese class I (moderate obesity) (30.00-34.99) & 6 & 13.3 \\
\hline Obese class II (severe obesity) (35.00-39.99) & 7 & 15.6 \\
\hline Obese class III (morbid obesity) (40.00) & 4 & 8.9 \\
\hline
\end{tabular}


Table (2): Percent distribution of character of burn of studied patients.

\begin{tabular}{|l|c|c|}
\hline \multirow{2}{*}{\multicolumn{1}{|c|}{ Items }} & \multicolumn{2}{c|}{ Studied patients (n=45) } \\
\cline { 2 - 3 } & No. & \% \\
\hline causes of burns was recorded: & & \\
\hline Flame \& Inhalation injury & 43 & 95.6 \\
\hline Electric & 1 & 2.2 \\
\hline Scalds & 1 & 2.2 \\
\hline Degree of burn: & & 55.5 \\
\hline Second & 25 & 4.4 \\
\hline Third & 2 & 40.1 \\
\hline Second \& Third & 18 & \\
\hline Burned body region: & & 26.8 \\
\hline head, neck, trunk, lower and upper limbs & 12 & 24.4 \\
\hline head, trunk and upper limbs & 11 & 4.4 \\
\hline lower limbs & 2 & 40.0 \\
\hline lower and upper limbs & 18 & 4.4 \\
\hline trunk and upper limbs & 2 & \\
\hline Total body surface area (\%TBSA): & & 24.6 \\
\hline $20 \%-29 \%$ & 7 & 60.0 \\
\hline $30 \%-39 \%$ & 11 & 27 \\
\hline $40 \%-100 \%$ & & \\
\hline
\end{tabular}

Table (3): Mean \pm SD of studied patients regarding vital signs

\begin{tabular}{|l|c|c|c|}
\hline \multirow{2}{*}{ Vital signs } & \multicolumn{3}{|c|}{ Studied patients $(\mathbf{n}=\mathbf{4 5})$} \\
\cline { 2 - 4 } & At admission & after 8hrs of admission & after 24hrs of admission \\
\cline { 2 - 4 } & Mean \pm SD & Mean \pm SD & Mean \pm SD \\
\hline Pulse rate & $100.2000 \pm 18.14161$ & $97.5556 \pm 14.12373$ & $97.0444 \pm 12.61304$ \\
\hline $\begin{array}{l}\text { Blood pressure } \\
\text { Systolic BP } \\
\text { Diastolic BP }\end{array}$ & $112.4222 \pm 16.08993$ & $112.0000 \pm 13.70965$ & $111.00 \pm 11.803$ \\
\hline Respiratory rate & $68.4000 \pm 10.41066$ & $69.3333 \pm 7.73128$ & $70.622 \pm 7.814$ \\
\hline Temperature & $24.9 \pm 2.9$ & $22.9 \pm 3.3$ & $24.0 \pm 9.2$ \\
\hline
\end{tabular}

On-way-ANOVA test $*$ Statistical significant differences $(p<0.05)$

Table (4): Percent distribution of studied patients related to Intra- abdominal pressure (IAP) monitoring

\begin{tabular}{|c|c|c|c|c|c|c|c|c|c|}
\hline \multirow{3}{*}{$\begin{array}{l}\text { IAP } \\
\text { Grade }\end{array}$} & \multicolumn{6}{|c|}{ studied patients $(n=45)$} & \multicolumn{3}{|c|}{ P-value } \\
\hline & \multicolumn{2}{|c|}{ At admission } & \multicolumn{2}{|c|}{$\begin{array}{c}\text { After } 8 \text { hrs of } \\
\text { admission }\end{array}$} & \multicolumn{2}{|c|}{$\begin{array}{l}\text { After } 24 \text { hrs of } \\
\text { admission }\end{array}$} & \multirow[t]{2}{*}{ P1 } & \multirow[t]{2}{*}{ P2 } & \multirow[t]{2}{*}{ P3 } \\
\hline & No & $\%$ & No & $\%$ & No & $\%$ & & & \\
\hline IAP Mean \pm SD & \multicolumn{2}{|c|}{$14.444 \pm 3.763$} & \multicolumn{2}{|c|}{$18.400 \pm 3.639$} & \multicolumn{2}{|c|}{$20.244 \pm 3.248$} & $\begin{array}{c}0.000 \\
* * *\end{array}$ & $\begin{array}{c}0.000 \\
* * *\end{array}$ & $\begin{array}{c}0.000 \\
* * *\end{array}$ \\
\hline $\begin{array}{l}\text { IAP grade } \\
\text { Grade } 0<\mathbf{1 2} \mathbf{m m h g}\end{array}$ & 14 & 31.1 & 0 & 0.0 & 0 & 0.0 & \multirow{5}{*}{$\begin{array}{c}0.003 \\
* *\end{array}$} & \multirow{5}{*}{$\begin{array}{c}0.001 \\
* *\end{array}$} & \multirow{5}{*}{$\begin{array}{c}0.031 \\
*\end{array}$} \\
\hline Grade $1 \quad \mathbf{1 2 - 1 5} \mathbf{m m h g}$ & 18 & 40.0 & 13 & 28.9 & 2 & 4.4 & & & \\
\hline Grade $2 \quad \mathbf{1 6 - 2 0} \mathbf{m m h g}$ & 8 & 17.8 & 16 & 35.6 & 22 & 48.9 & & & \\
\hline $\begin{array}{ll}\text { Grade } 3 & \mathbf{2 1 - 2 5} \mathbf{m m h g}\end{array}$ & 5 & 11.1 & 15 & 33.3 & 20 & 44.4 & & & \\
\hline Grade $4 \quad>\mathbf{2 5} \mathbf{m m h g}$ & 0 & 0.0 & 1 & 2.2 & 1 & 2.2 & & & \\
\hline
\end{tabular}

Independent sample T test $\quad *$ Statistical significant differences $(p \leq 0.05)$

$P l=$ significant differences between at admission \& after 8hrs of admission.

$P 2=$ significant differences between at admission \& after 24 hrs of admission.

$P 3=$ significant differences between after 8hrs of admission \& after 24 hrs of admission. 
Table (5): distribution of studied patients regarding to amount of IV Fluids and urine output.

\begin{tabular}{|c|c|c|c|c|c|c|c|c|}
\hline \multirow{4}{*}{ Time } & \multicolumn{8}{|c|}{ Study group $(n=45)$} \\
\hline & \multicolumn{4}{|c|}{ Amount IV of fluid } & \multicolumn{4}{|c|}{ Urine output } \\
\hline & \multirow{2}{*}{ Mean \pm SD } & \multicolumn{3}{|c|}{ p-value } & \multirow{2}{*}{ Mean \pm SD } & \multicolumn{3}{|c|}{ p-value } \\
\hline & & P1 & $\mathbf{P 2}$ & $\mathbf{P 3}$ & & P1 & $\mathbf{P 2}$ & $\mathbf{P 3}$ \\
\hline First 8hrs of injury & $6297.77 \pm 2441.08$ & \multirow{3}{*}{ 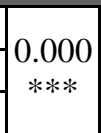 } & \multirow{3}{*}{$\begin{array}{c}0.000 \\
* * *\end{array}$} & \multirow{3}{*}{$\begin{array}{c}0.000 \\
* * *\end{array}$} & $1418.88 \pm 643.43$ & \multirow{3}{*}{$\begin{array}{l}0.000 \\
* * *\end{array}$} & \multirow{3}{*}{$\begin{array}{c}0.006 \\
*\end{array}$} & \multirow{3}{*}{0.060} \\
\hline Second $8 \mathrm{hrs}$ of injury & $3126.66 \pm 1230.05$ & & & & $1196.88 \pm 771.82$ & & & \\
\hline Third 8hrs of injury & $3137.77 \pm 1244.91$ & & & & \begin{tabular}{|l|}
$1131.77 \pm 581.11$ \\
\end{tabular} & & & \\
\hline Total & $\begin{array}{c}9424.444 \pm \\
3668.193\end{array}$ & & & & $\begin{array}{l}3747.55 \pm \\
1560.043\end{array}$ & & $.000^{* * * *}$ & \\
\hline IO balance & \multicolumn{8}{|c|}{$5676.888 \pm 2108.15$} \\
\hline
\end{tabular}

Independent sample T test

* Statistical significant differences $(p<0.05)$

$P 1=$ significant difference between Firs t8hrs of injury \& Second 8hrs of injury.

$P 2=$ significant difference between First 8hrs of injury \& Third 8hrs of injury.

$P 3=$ significant difference between Second 8hrs of injury \& Third 8hrs of injury.

Table (6): Distribution of studied patients regarding Risk factors of ACS and IAH

\begin{tabular}{|c|c|c|c|c|c|}
\hline \multirow{3}{*}{ Risk factors assessment } & \multicolumn{4}{|c|}{ Studied patients $(n=45)$} & \multirow{3}{*}{ P value } \\
\hline & \multicolumn{2}{|c|}{$\begin{array}{c}\text { Normal } \\
\text { No. } 14\end{array}$} & \multicolumn{2}{|c|}{$\begin{array}{c}\text { IAH } \\
\text { No. 31 }\end{array}$} & \\
\hline & No. & $\%$ & No. & $\%$ & \\
\hline \multicolumn{5}{|l|}{ Origin of burns was recorded: } & \multirow{4}{*}{0.049} \\
\hline Flame & 14 & 100 & 29 & 93.54 & \\
\hline Electric & 0 & 0.0 & 1 & 3.22 & \\
\hline Scalds & 0 & 0.0 & 1 & 3.22 & \\
\hline \multicolumn{5}{|l|}{ Degree of burn: } & \multirow{4}{*}{$0.005^{* *}$} \\
\hline Second & 9 & 64.28 & 16 & 51.61 & \\
\hline Third & 0 & 0.0 & 2 & 6.45 & \\
\hline Second \& Third & 5 & 35.71 & 13 & 41.93 & \\
\hline \multicolumn{5}{|l|}{ Burned body region: } & \multirow{6}{*}{0.041} \\
\hline head, neck, trunk, lower and upper limbs & 7 & $50 \%$ & 5 & 16.12 & \\
\hline head, trunk and upper limbs & 4 & 28.57 & 7 & 22.58 & \\
\hline lower limbs & 0 & 0.0 & 2 & 6.45 & \\
\hline lower and upper limbs & 2 & 14.28 & 16 & 51.61 & \\
\hline trunk and upper limbs & 1 & 7.14 & 1 & 3.22 & \\
\hline
\end{tabular}

Chi-square Test

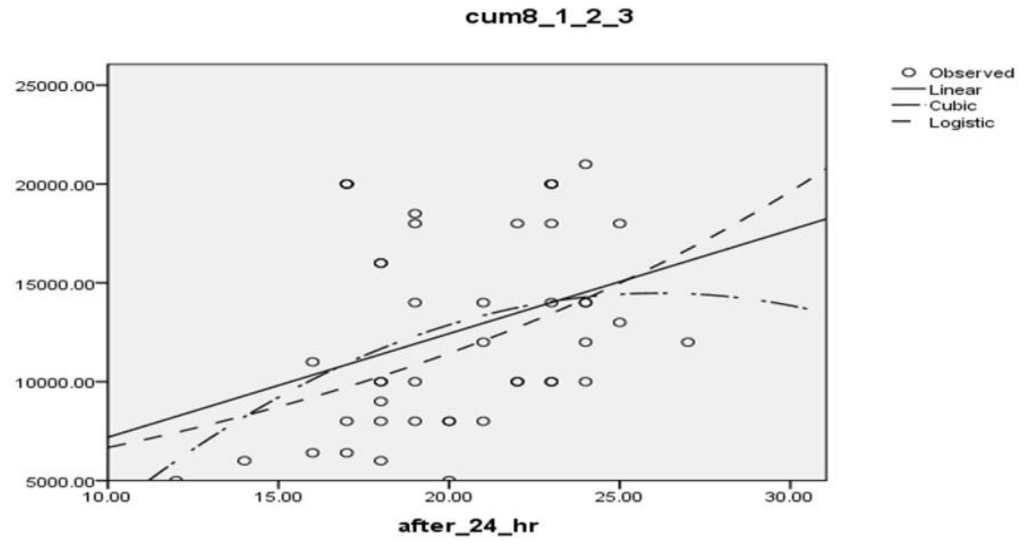

Figure (1): Correlation between IV Fluids \& IAP. 


\section{Types of fluid}

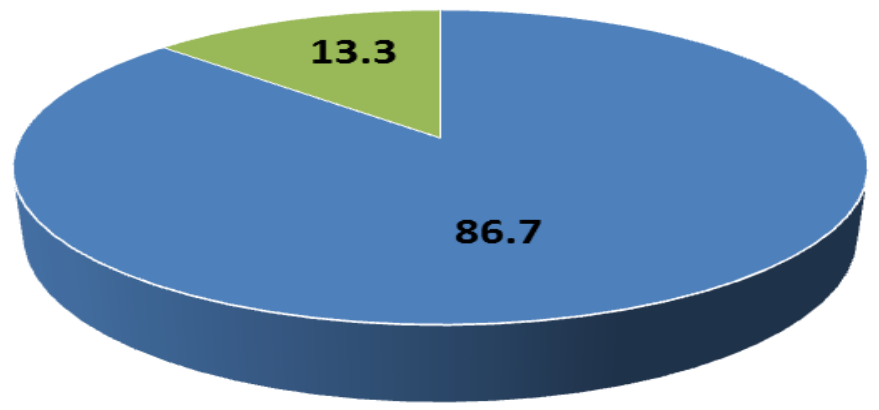

- Ringer Lactate - Sodium

Figure (2): Percentages distribution of studied patients according to Types of fluid.

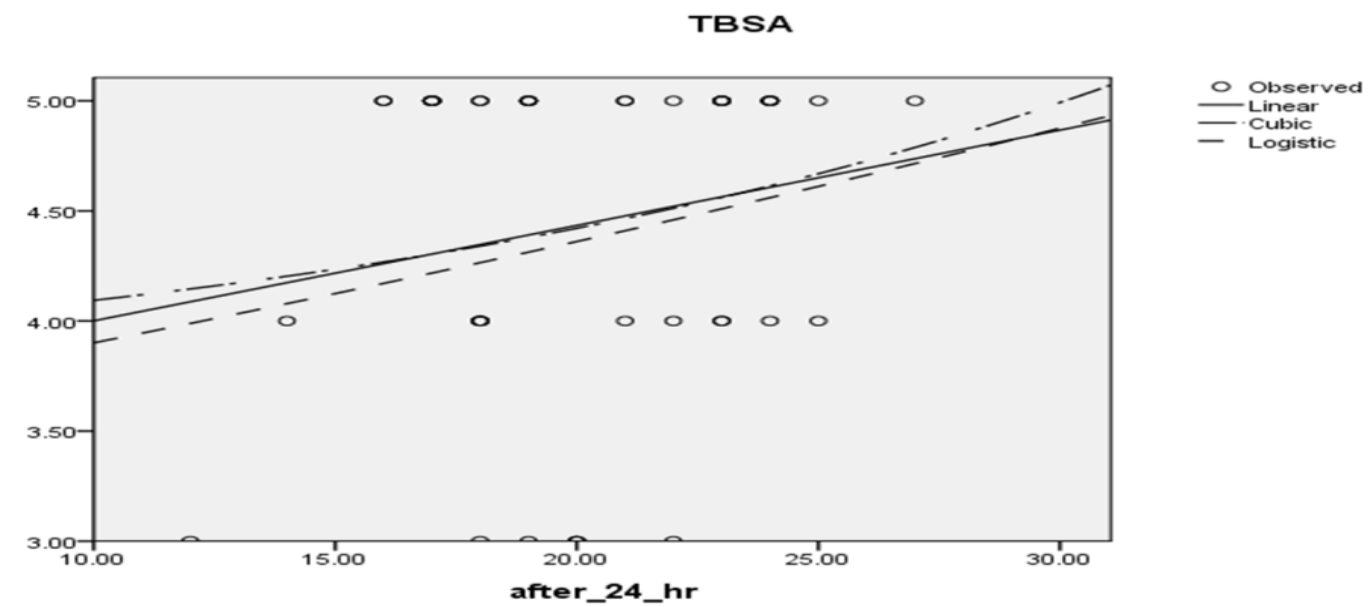

Figure (3): Correlation between TBSA \& IAP.

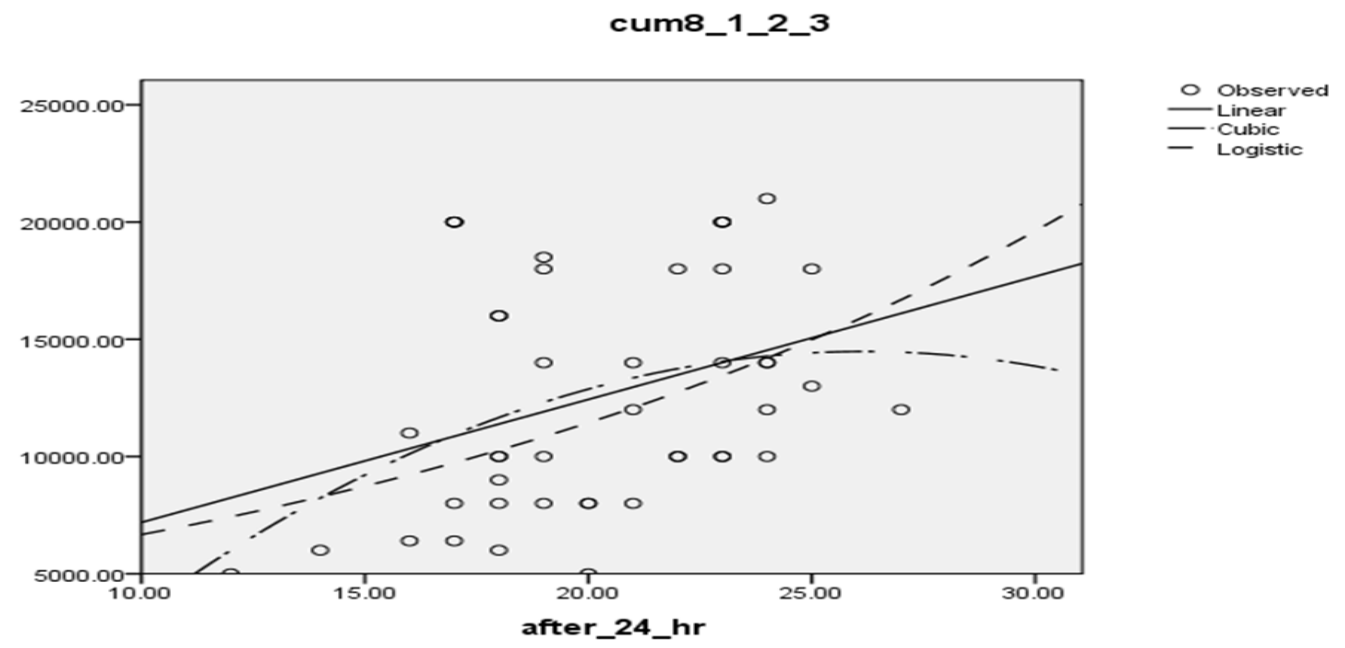

Figure (4): Correlation between amounts of Fluids \& IAP. 
Table (7): Distribution of studied patients regarding (length stay \& mortality \& complication) and IAH:

\begin{tabular}{|c|c|c|c|c|c|}
\hline \multirow{3}{*}{ Items } & \multicolumn{4}{|c|}{ Study group $(n=45)$} & \multirow{3}{*}{$P$ value } \\
\hline & \multicolumn{2}{|c|}{$\begin{array}{c}\text { Normal } \\
\text { No. } 14\end{array}$} & \multicolumn{2}{|c|}{$\begin{array}{c}\text { IAH } \\
\text { No. 31 }\end{array}$} & \\
\hline & No. & $\%$ & No. & $\%$ & \\
\hline \multicolumn{5}{|l|}{ Length of stay: } & \multirow{3}{*}{0.56} \\
\hline Less than 1 month & 13 & 92.85 & 27 & 87.09 & \\
\hline More than 1 month to 3 months & 1 & 7.14 & 4 & 12.90 & \\
\hline \multicolumn{5}{|l|}{ Mortality: } & \multirow{3}{*}{0.58} \\
\hline yes & 6 & 42.85 & 16 & 51.61 & \\
\hline no & 8 & 57.14 & 15 & 48.38 & \\
\hline \multicolumn{5}{|l|}{ Complication: } & \multirow{3}{*}{$0.000^{*}$} \\
\hline Yes & 6 & 42.85 & 31 & 100.0 & \\
\hline No & 8 & 57.14 & 0 & 0 & \\
\hline
\end{tabular}

Chi-square Test

Table (1): Shows that mean and SD ages for the burns patients were $39.1 \pm 15.2$. More than half of patients were male with percentage $55.6 \%$. Third of the patients were overweight with percentage $28.9 \%$.

Table (2): Illustrates that vast majority of patients were burn by flam with percentage $95.6 \%$. More than half of patients were at second degree of burn with percentage $55.5 \%$.Nearly to half of patients were burned in lower and upper limbs of the body with percentage $40.0 \%$. More than half of patients had $40 \%$ to $100 \%$ of total body surface area burned with percentage $60.0 \%$.

Table (3): Demonstrates that there was statistical significant difference between at admission \& After $24 \mathrm{hrs}$ of admission regarding to Pulse rate and Blood pressure. There was no statistical significant difference between all period during first $24 \mathrm{hrs}$ from admission regarding to respiratory rate and temperature.

Table (4): This table found that, as regard of Intraabdominal pressure monitoring, results revealed that was statistical significant difference between time intervals throughout the first $24 \mathrm{hrs}$ from admission

Table (5): Shows that, as regard to Amount of IV fluid and urine output the result revealed that, there was highly statistical significant difference between all periods during first $24 \mathrm{hrs}$ of admission.

Table (6): Found relation between risk factors of ACS and IAH that, regarding to Origin of burns, result revealed that Vast Majority of patients was burned by flam had IAH with percentage $93.54 \%$. Regarding to Degree of burn, results revealed that more than half of the patients at second degree had IAH with percentage $51.61 \%$. Regarding to Burned body region, result revealed that most patients were burned in lower and upper limbs had IAH with percentage $51.61 \%$.
Table (7): Shows that, regarding to Length of stay at burn unit, result revealed that majority of patients that had IAH had stayed at burn unit less than 1 month with percentage $87.09 \%$.More than half of patients had IAH died with percentage $51.61 \%$. All patients at IAH had complications with percentage $100.0 \%$.

Figure (1): Illustrates that, there was positive Correlation between IAP and IV Fluids

Figure (2): Shows that, most of patient used ringer lactate as a type of fluid with percentage $86.7 \%$

Figure (3): Demonstrates that, there was positive a Correlation between TBSA \& IAP

Figure (4): Illustrates that, there was positive Correlation between IAP and Fluids

\section{Discussion}

Burn patients are at high risk of secondary intraabdominal hypertension (IAH) and abdominal compartment syndrome (ACS) due to capillary leak and large volume fluid resuscitation. (Wise et al., 2016).

Measure of IAP is essential in critically ill burn patients because of the potentially fatal consequences of IAH and ACS. Physiological changes occur with increases in IAP that affect nearly every organ system (Mcbeth et al., 2014).

The present study revealed that, more than half of patients were males with the mean and SD ages were thirty nine from the researcher point of view the incidence was higher in middle aged males because they are more active and powerful in the case of incident to protect other family members and valuable things at house. This is in line with (Hosseini et al., 2017), who found in his study that about two thirty of the patients were males with mean age were twenty five years old. Also, the present result disagreement with (Gupta et al., 2011) study 
showed that, the age group between fifteen and forty five years.

In this study the results showed that, the majority of patients were burn by flam. This may be related to low socioeconomic status lead to use of unsafe flams, inadequate health education and nearly absence of first aids equipment at all Egyptian house. This result was disagreement with the study done by (Hosseini et al., 2017) who demonstrated that the most common causes of burn were hot liquids, gas explosion and fire, respectively.

The present findings of this study showed that half of patients had $40 \%$ to $100 \%$ of total body surface area burned. This is on line with a study conducted by (Mcbeth et al., 2014) who showed the average TBSA burn was $31.4 \pm 20.9 \%$ (range: $5-95 \%$ ).

In the present study, regarding to burn body region, the result reveled that, there were nearly half of patients were burned in lower and upper limbs. This may be due to the upper and lower limbs are the most used body part during trials to Fire extinguishers and securing self and others. This is in line with the study done by (McBeth et al., 2014) who found that majority of burns were to the face (44.6\%) and upper extremity (52.6\%) including hands.

Regarding to vital signs, the present study showed there was statistical significant between at admission and after $24 \mathrm{hrs}$ of admission regarding pulse rate and blood pressure related to the patient received suitable amount of fluid that help to stable hemodynamic statues of the burned patients. Moreover, there were no statistical significant between time interval throughout the first $24 \mathrm{hrs}$ of admission regarding to respiratory rate and temperature ,this due to inhalation injury and skin loss results in an inability to regulate body temperature of burned patients. This disagreement with (Abd El Aziz et al., 2015) who revealed that no statistical significant difference a bout patients' pulse rate and systolic and diastolic blood pressure. On the other hand, agreement with his study that showed no statistical significant difference regarding to patients' temperature and respiratory rate.

The present study demonstrated that regarding to Intra-abdominal pressure monitoring there was statistical significant difference between all periods during first $24 \mathrm{hrs}$ from admission. This concurs with the fact that the patients tend to receive aggressive fluid resuscitation in the first days through using the Parkland's formula. This finding of the present study was agreed with (Mbiine et al., 2017) who her studied revealed that, the incidence of IAH is higher in the first two days at 17.4 cases per 100 person days but declined over the next five days.

As regard to amount of fluid, the present study showed that, there was statistical significant difference between amount of fluid which patients received between first $8 \mathrm{hrs}$ of injury, second $8 \mathrm{hrs}$ of injury and third 8hrs of injury. Majority of patients used ringer lactate as a type of IV fluid this due to that the patients in the first $8 \mathrm{hrs}$ needs more fluid to supplement the lost amount of fluid pre hospital admission ringer lactate was the most suitable to burned patients .Also, this related to use the Parkland formulas to burned patient. This result is agreement with (Mitra et al., 2006) who studies shows that significantly more fluid was given than predicted by the Parkland formula. Ringer lactate was used for $74.9 \%$ of the resuscitation volume in $24 \mathrm{hrs}$.

The present study showed that more than half of patients developed intra-abdominal hypertension due to pathological changes after burn. This result is agreement with (Talizin et al., 2018) who studied acute kidney injury and intra-abdominal hypertension in burn patients in intensive care unit at Brazil They found that the most of patients developed intraabdominal hypertension.

Current study showed that about vast majority of patients were burned by flam had IAH. Similarly, results were shown by (McBeth et al., 2014) study who founded that Intra-abdominal pressure increased with the severity of inhalation injury.

In the current study, result revealed that more than half of patients were burned in lower and upper limbs had IAH due to etiology of burned injury. The present study is disagreement with (Mbiine et al., 2017) who reported that the prevalence of IAH at admission was far greater in the patients that had abdominal eschars.

In the current study, the result shows that, there was positive correlation between IAP and TBSA. This due to increase in capillary permeability that occurs in severe burn patients contributes to extensive edema formation that caused elevated IAP. There is agreement with (strang et al., 2014) that this result showed IAH prevalence is $64.7-74.5 \%$ among patients with $\geq 20 \%$ TBSA burned

Regarding to amount of IV fluids intake during first $24 \mathrm{hrs}$, the current study showed there was positive correlation between IAP and IV Fluids .This is due to the large volume of fluids resuscitation, decreased abdominal wall compliance, and increased capillary leakage bowel oedema. Similarly, this finding supported by (Wise et al., 2016) that this result showed there are a correlation between IAP and total administered fluid volume has been reported.

The present study, regarding to length of stay the result revealed that majority of patients that had IAH had stayed at burn unit less than one month this due to complication that occur result IAH .These disagree with the study done by (wise et al., 2016) who 
showed that the length of ICU and hospital stays $(23.9 \pm 25.7$ and $48.4 \pm 72.3$ respectively).

The findings of the present study showed that more than half of patients had IAH died. All patients at IAH had complications, this related to organ dysfunction due to intra-abdominal hypertension. Similarly, this finding supported by ( Mbiine et al., 2017) found that The mortality in the IAH group was more than eighty precent and commonly the renal and cardiovascular systems are the most affected.

\section{Conclusions}

Based on the results of the present study, it can be concluded that most of patients with $>20 \%$ TBSA burned presented a very high prevalence of IAH.

ACS and IAH are frequently seen devastating complications in severely burned patients, so the burned patients need to close monitoring and measurement of IAP.

\section{Recommendations}

Based on the results of the present study, the following recommendations were suggested:

- The Burn Unit needs to design protocols for monitoring and management of intra-abdominal hypertension and abdominal compartment syndrome.

- Health team needs to educational program about IAP measurement methodology and knowledge about IAH and its clinical implications.

- Reapply this research on a larger probability sample acquired from different geographical area in Egypt for generalization

\section{Reference}

1. Abd El Aziz A., Mostafa S., El-Gamil A., Mahmoud H.,(2015): Effect of Ozone Therapy Dressing Technique on the Healing Process of Recent 2nd Degree Burns, IOSR Journal of Nursing and Health Science, Vol (4), Issue 4, P.P 26-49.

2. Barbosa A., Calvi S., Pereira P., (2009): Nutritional, immunological and microbiological profiles of burn patients., Journal Venom Anim Toxins incl Trop Dis, Vol(15), n(4), p.(768-777), ISSN 1678-9199

3. Berry N., \& Fletcher S., (2012):Abdominal compartment syndrome, British Journal of Anaesthesia, Vol(12), Number(3), PP.194-200.

4. Espinoza G., Aragon V., Villalobos E., Manzano R., \& Antonio B., (2017): Burns: Definition, Classification, Pathophysiology and Initial Approach, Gen Med (Los Angeles), vol (5), Issue (5): doi:10.4172/2327-5146.1000298

5. Gupta A., Uppal S., Garg R., Gupta A., \& Pal1 R., (2011): A clinico-epidemiologic study of 892 patients with burn injuries at a tertiary care hospital in Punjab, India, Journal of Emerganciy Trauma and Shock, Vol.4(No.1),P.P 7-11.

6. Hosseini S., Rashtchi V., Kamali K., \& Moghimi M., (2017): Epidemiology and outcome of 2,590 burned patients in Northwest Iran, Ann Burns Fire Disasters, Vol. 30(No.2), P.P 85-90.

7. James E., Hayes M., McCabe P., Williams G., Takata M., \& Vizcaychipi M., (2012): Fluid creep in burn resuscitation: the tide has not yet turned. Critical Care ,Vol. 16(No.3),P.P 111189.

8. kollias S., Stampolidis N., kourakos P., Mantzari E, Koupidis S., Tsaousi S., Dimitrouli A., Atiyeh B., \& Castana O., (2015), Abdominal compartment syndrome (ACS) in a severely burned patient, Ann Burns Fire Disasters, Vol. 28(No.1),PP. 5-8.

9. Malbrain, M., De Keulenaer B., Oda J., De laet L., De Waele J., Roberts D., Kirkpatrick A ., Kimball E., \& Ivatury R., (2015): Intra-abdominal hypertension and abdominal compartment syndrome in burns, obesity, pregnancy, and general medicine. www. ait. viamedica.pl. Anaesthesiology Intensive Therapy;Vol.47 (No.3), P.P 228-240.

10. Mbiine R., Alenyo R., Kobusingye O., Kuteesa J., Nakanwagi C., Lekuya H ., Kituuka O., \& Galukande M., (2017): Intraabdominal hypertension in severe burns: prevalence, incidence and mortality in a subSaharan African hospital International Journal Burn Trauma ,vol.7(No.6),PP.80-87.

11. Mcbeth P ., Sass k, Nickerson D., Ball C ., \& Kirkpatrick A., (2014): A necessary evil ,intraabdominal hypertension complicating burn patient resuscitation, Jourrnal of trauma management out comes, Vol. 8(No.12), P.P 5297.

12. Mitra B., Fitzgerald M., Cameron P., \& Cleland H., (2006): Fluid resuscitation in major burns, ANZ J. Surg, Vol. 76(No.2),P.P 35-38.

13. Strang, S., Lieshout, E., Breederveld, R., Van Waes, O., \& Erasmus, M., (2014): A Systematic Review on Intra-Abdominal Pressure, Volume 40, Issue 1, Pages 9-16

14. Talizin T., Tsuda M., Tanita M., Moro I., Festti J., Dantas C., Carvalho C., \& Queiroz L., (2018); Acute kidney injury and intraabdominal, Revista Brasileira De Terapia Intensiva, Vol. 30(No.1),P.P 15-20

15. Tanga K., Jianb L., Qinb Z., Gomez M., \& Beveridgea M., (2006): Characteristics of burn 
patients at a major burn center in Shanghai, Burns, Vol 32, Issue 8, P.P 1037-1043

16. Walker J., \& Criddle L., (2003): Pathophysiology and Management of Abdominal Compartment Syndrome ,American Journal of Critical Care,Vol. 12(No.4), P,P367371.

17. Wise R., Jacobs J., Pilate S., Jacobs A., Peeters Y., Vandervelden S., Van Regenmortel N., De Laet I., Schoonheydt K., Dits H., \& Malbrain M., (2016): Incidence and prognosis of intra-abdominal hypertension and abdominal compartment syndrome in severely burned patients: pilot study and review of the literature, Anaesthesiol Intensive Therapy, Vol 48 (No.4),P.P 95-109. 